\title{
How should we treat iatrogenic aortic dissection as a complication of percutaneous intervention?
}

\author{
Hrvoje Stipić*, Igor Šesto, Tomislav Šipić, Davor Richter, Krešimir Štambuk, Robert Bernat \\ Clinic for Cardiovascular Disease Magdalena, Krapinske Toplice, Croatia
}

latrogenic acute dissection of the ascending aorta following coronary angiography and percutaneous intervention is rare with an overall incidence of $0.02 \%$. We report four cases of aortic dissection during coronary angioplasty with a disparate evolution that was due to the different location of the entry port of the dissection. Three cases of iatrogenic coronary dissection with extensive propagation into the ascending aorta during angioplasty of the right coronary artery are presented. The aortic dissection was successfully treated by stenting at the right coronary artery ostium. Follow-up computed tomography and coronary angiography showed complete resolution of aortic dissection. One case of coronary dissection of LAD/LMCA with propagation into the ascending aorta required surgical intervention. This case also has angiographic and computed tomography follow-up. We conclude that most of localized aortic dissections can be treated by sealing the entry point with a coronary stent. However, more extensive dissections may require a surgical intervention.

KEYWORDS: aortic dissection, percutaneous intervention, right coronary artery.

*Address for correspondence: Magdalena - klinika za kardiovaskularne bolesti, Ljudevita Gaja 2, HR-49217 Krapinske Toplice, Croatia.

Phone: +385-49-244-444

E-mail: hrvoje.stipic@magdalena.hr 